\title{
Oxidation - Nitridation of Ni-Cr-Al Alloys
}

\author{
Susan Han ${ }^{\mathrm{a}, \mathrm{b}} *$, David John Young ${ }^{\mathrm{a} *}$ \\ ${ }^{a}$ School of Materials Science \& Engineering, University of New South Wales \\ Sydney, 2052, Australia \\ ${ }^{\mathrm{b}}$ Current address: \#701, 816 4th Ave SW, Calgary, AB T2P 2Y1, Canada
}

Received: September 2, 2002; Revised: September 4, 2002

\begin{abstract}
A series of alloys containing 24-36 wt pet $\mathrm{Cr}$ and $13.5-25.0$ wt pct $\mathrm{Al}$ was reacted with air at $1100{ }^{\circ} \mathrm{C}$ for $260 \mathrm{~h}$. The products of isothermal reaction were scales of $\alpha-\mathrm{Al}_{2} \mathrm{O}_{3}$ plus small amounts of $\mathrm{Cr}_{2} \mathrm{O}_{3}$. These grew according to parabolic kinetics, interrupted by episodic weight losses caused by partial spallation. No nitridation occurred during the isothermal exposures. Reaction during thermal cycling for up to 260 one hour cycles was much more severe. Repeated scale spallation led to subsurface alloy depletion in aluminium and, to a lesser extent, chromium. This caused transformation of the prior alloy three-phase structures $(\alpha-\mathrm{Cr}+\beta-\mathrm{NiAl}+\gamma-\mathrm{Ni})$ to single-phase $\gamma$ nickel solution. Destruction of the external scale allowed gas access to this metal which was able to dissolve both oxygen and nitrogen. Inward diffusion of the two oxidants led to development of a complex internal precipitation zone: $\mathrm{Al}_{2} \mathrm{O}_{3}$ and $\mathrm{Cr}_{2} \mathrm{O}_{3}$ beneath the surface, then $\mathrm{Al}_{2} \mathrm{O}_{3}$ then $\mathrm{AIN}$, then $\mathrm{AIN}+\mathrm{Cr}_{2} \mathrm{~N}$ and finally AIN alone in the deepest region. Diffusion-controlled kinetics were in effect initially, but mechanical damage to the internal precipitation zone led to more rapid gas access and approximately linear kinetics in the long term.
\end{abstract}

Keywords: Thermal cycling, Diffusion, Precipitation, Solubility product, Ni-Cr-Al alloys, Air

\section{Introduction}

Because nitrogen is present in air and combustion gases, nitridation of alloys is in principal to be expected if their oxide scales are permeable to nitrogen. Chromium oxide scales are known ${ }^{1,2}$ to transmit nitrogen, and $\mathrm{Cr}_{2} \mathrm{~N}$ forms either as a sub-scale layer or as internal precipitate. This effect can be expected to be more severe under thermal cycling conditions which lead to oxide scale damage, reducing its effectiveness as a barrier to nitrogen ${ }^{3,4}$.

Alumina scales might be expected to provide better protection against nitrogen entry. However, an examination of the behaviour of alumina-forming $\mathrm{Ni}-\mathrm{Cr}-\mathrm{Al}$ alloys under thermal cycling conditions ${ }^{5}$ has shown that a complex pattern of internal oxidation and nitridation is developed.

Alumina forming nickel based materials are of interest as corrosion resistant coatings for superalloy components. The present work was concerned with comparing the behaviour of three-phase $(\alpha-\mathrm{Cr}+\beta-\mathrm{NiAl}+\gamma-\mathrm{Ni})$ alloys under isothermal and temperature cycling conditions.

*e-mail: msshanhan@hotmail.com,d.young@unsw.edu.au Presented at the International Symposium on High Temperature Corrosion in Energy Related Systems, Angra dos Reis - RJ, September 2002.

\section{Experimental methods}

Nine ternary alloys were argon-arc melted and then annealed under flowing argon for $24 \mathrm{~h}$ at $1100^{\circ} \mathrm{C}$. Alloy compositions measured by electron probe micro-analysis (EPMA) and constituent phase volume fractions measured by automated image analysis, using an optical microscope, are listed in Table 1. The latter were in good agreement with equilibrium values calculated from the phase diagram and constituent phase densities.

Individual oxidation samples were cut from the alloys, their surfaces ground to a 1200 grit finish and ultrasonically cleaned in acetone immediately before use. The samples were then subjected to temperature cycling oxidation at $1100{ }^{\circ} \mathrm{C}$ in still laboratory air. Each cycle consisted of one hour at temperature and $15 \mathrm{~min}$ at ambient. Sample weight changes were measured periodically between oxidation cycles. The temperature cycling experiments were supplemented by isothermal kinetic measurements using an automatic microbalance. 
Reaction products were characterised using standard metallographic techniques, including the measurement of internal precipitation depths.

\section{Results}

Isothermal weight gain kinetics were approximately parabolic, interrupted by episodic weight losses as exemplified by the data in Fig. 1. The early stage of reaction, before any obvious weight loss occurred, was also approximately parabolic (Fig. 2). The data were regressed on the Eq. (1):

$$
(\Delta \mathrm{W} / \mathrm{A})^{2}=\mathrm{k}_{\mathrm{p}} \mathrm{t}+\mathrm{C}
$$

where $\Delta$ W/A denotes weight change per unit area arrived at

Table 1. Alloy compositions (at. pct.) and phase constitutions (volume fraction).

\begin{tabular}{lccccc}
\hline Alloy & $\mathrm{Cr}$ & $\mathrm{Al}$ & $\alpha-\mathrm{Cr}$ & $\beta-\mathrm{NiAl}$ & $\gamma$-Ni \\
\hline 1 & 31.0 & 20.7 & 0.18 & 0.56 & 0.27 \\
2 & 36.4 & 14.1 & 0.11 & 0.30 & 0.59 \\
3 & 24.8 & 24.6 & 0.15 & 0.72 & 0.13 \\
4 & 37.6 & 19.0 & 0.30 & 0.53 & 0.17 \\
5 & 24.2 & 21.7 & 0.09 & 0.53 & 0.38 \\
6 & 35.6 & 18.0 & 0.26 & 0.40 & 0.34 \\
7 & 24.3 & 22.3 & 0.09 & 0.60 & 0.32 \\
8 & 31.3 & 14.7 & 0.07 & 0.34 & 0.59 \\
9 & 29.5 & 24.0 & 0.21 & 0.71 & 0.08 \\
\hline
\end{tabular}

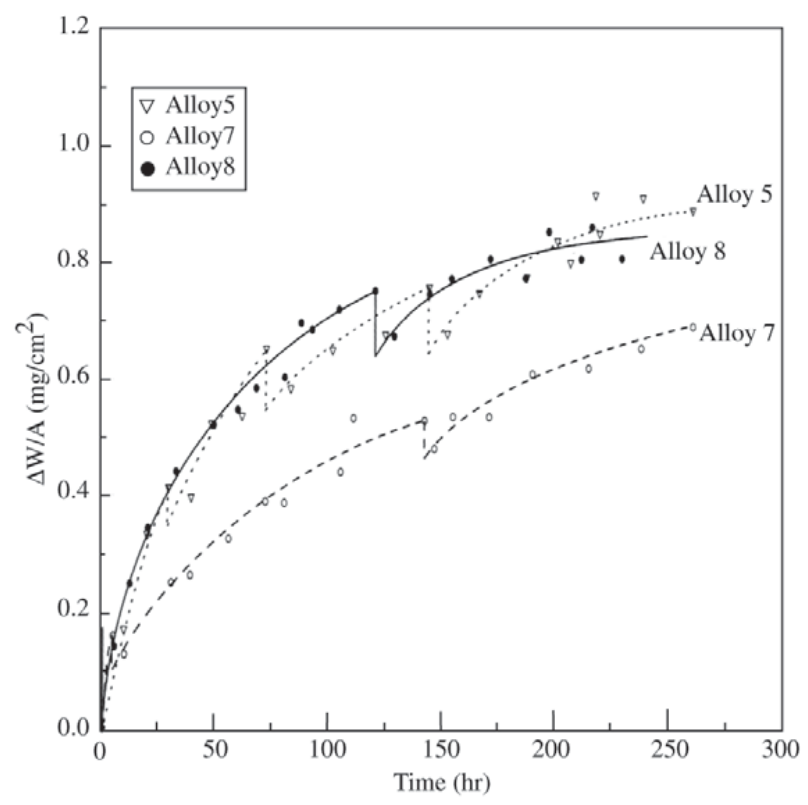

Figure 1. Weight uptake kinetics during isothermal oxidation. in time $\mathrm{t}$, and $\mathrm{k}_{\mathrm{p}}$ and $\mathrm{C}$ are constants. Two values of the rate constant, $\mathrm{k}_{\mathrm{p}}$, were arrived at : an average for the full data set over $260 \mathrm{~h}$ and an estimate for the first $24 \mathrm{~h}$, in each case ignoring discontinuities in the weight uptake curves. The results are summarised in Table 2.

After cooling from reaction temperatures, alloys 1,5 and 7 retained their scales apparently intact, but the others sustained substantial degrees of scale loss. In situ analysis by $\mathrm{X}$-ray diffraction (XRD) of the oxidised surfaces produced characteristic patterns for $\alpha-\mathrm{Al}_{2} \mathrm{O}_{3}, \gamma-\mathrm{Ni}$ and $\alpha$-Cr for all alloys. In addition, a small amount of $\mathrm{Cr}_{2} \mathrm{O}_{3}$ (distinguished from $\mathrm{Al}_{2} \mathrm{O}_{3}$ by d-spacing values) was detected on every alloy except 5 and 7. No $\mathrm{NiO}$ or $\mathrm{NiCr}_{2} \mathrm{O}_{4}$ was ever detected.

Examination of metallographic sections after $260 \mathrm{~h}$ of isothermal oxidation yielded the results shown in Fig. 3. The fragile oxide scales could not be preserved

Table 2. Parabolic rate constant $\left(\mathrm{mg}^{2} / \mathrm{cm}^{4} \mathrm{~S}^{-1}\right)$ for isothermal oxidation.

\begin{tabular}{ccc}
\hline Alloy & $\begin{array}{c}\text { Average rate } \\
10^{6} \mathrm{k}_{\mathrm{p}}\end{array}$ & $\begin{array}{c}\text { Rate in first } 24 \mathrm{~h} \\
10^{6} \mathrm{k}_{\mathrm{p}}\end{array}$ \\
\hline 1 & 0.7 & 0.2 \\
2 & 0.6 & 0.6 \\
3 & 1.0 & 1.7 \\
4 & 0.8 & 1.0 \\
5 & 0.9 & 1.6 \\
6 & 0.3 & 0.6 \\
7 & 0.5 & 0.5 \\
8 & 1.0 & 1.7 \\
9 & 1.4 & 0.2 \\
\hline
\end{tabular}

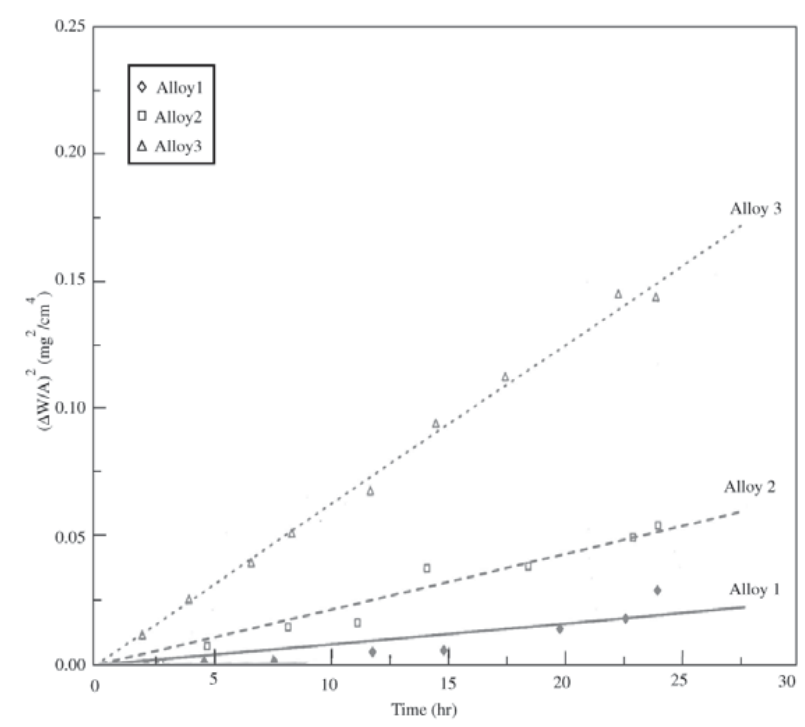

Figure 2. Parabolic plots of early stage oxidation. 
through the mounting procedure, and were never visible metallographically. No internal oxidation products were found in any alloy, but all had undergone subsurface phase transformations. The four patterns of alloy phase transformation found are shown in Fig. 3. The phases present were identified by EPMA: the bright white phase is $\alpha-\mathrm{Cr}$, the mid grey phase $\beta$-NiAl and the light grey one $\gamma$-Ni. Alloys $1,2,4,6$ and 9 developed a single subsurface zone of $\alpha+\gamma$ (Fig. 3a); Alloy 3 developed successive zones of $\alpha+\gamma$, then $\gamma$ and then $\gamma+\beta$ (Fig. 3b); Alloys 5 and 7 developed two zones, $\gamma$ at the surface, and $\gamma+\beta$ beneath (Fig. 3c); Alloy 8 developed a single $\gamma$-phase layer, but with particles of $\alpha-\mathrm{Cr}$ visible at the external surface (Fig. 3d).

Weight change kinetics during cyclic oxidation are shown in Fig. 4. All alloys experienced initial weight losses. The rate of weight loss slowed with time until a period of net weight increase followed. Alloy 3 soon commenced to gain weight, and continued to do so at a rapid, linear rate. The other alloys gained weight much more slowly.

Thermally cycled alloy surfaces suffered extensive scale spallation. Analysis by XRD of the surfaces after reaction showed $\gamma$-Ni to be the major phase, with smaller amounts of $\mathrm{Al}_{2} \mathrm{O}_{3}, \mathrm{Cr}_{2} \mathrm{O}_{3}, \mathrm{NiCr}_{2} \mathrm{O}_{4}$ and, in the case of Alloy 7, $\mathrm{NiO}$. Metallographic cross-sections revealed large quantities of internal corrosion products, and a typical example is shown in Fig. 5. Microprobe analysis identified the precipitates. The large, irregular precipitates beneath the alloy surface were $\mathrm{Cr}_{2} \mathrm{O}_{3}$ and $\mathrm{Al}_{2} \mathrm{O}_{3}$, the faceted and needle-shaped precipitates in the wide, inner zone were AIN and the light coloured particles were $\mathrm{Cr}_{2} \mathrm{~N}$. A typical analysis is shown i

Fig. 6. It is seen that the metal matrix containing the precipitates is $\gamma$-nickel. This was the case for all alloys, and transformation fronts were clearly visible at or ahead of the internal nitride precipitation front.

\section{Discussion}

\subsection{Isothermal Reaction}

Under isothermal conditions, all alloys formed external scales, the remnants of which after spallation were princi-
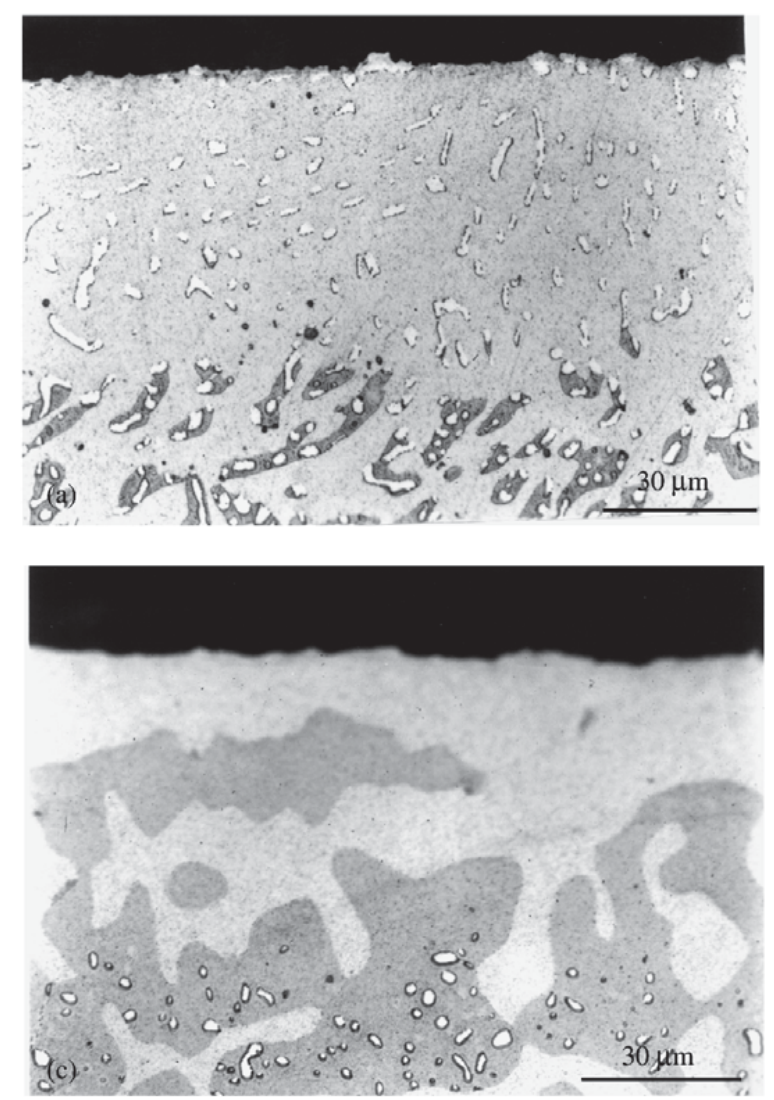
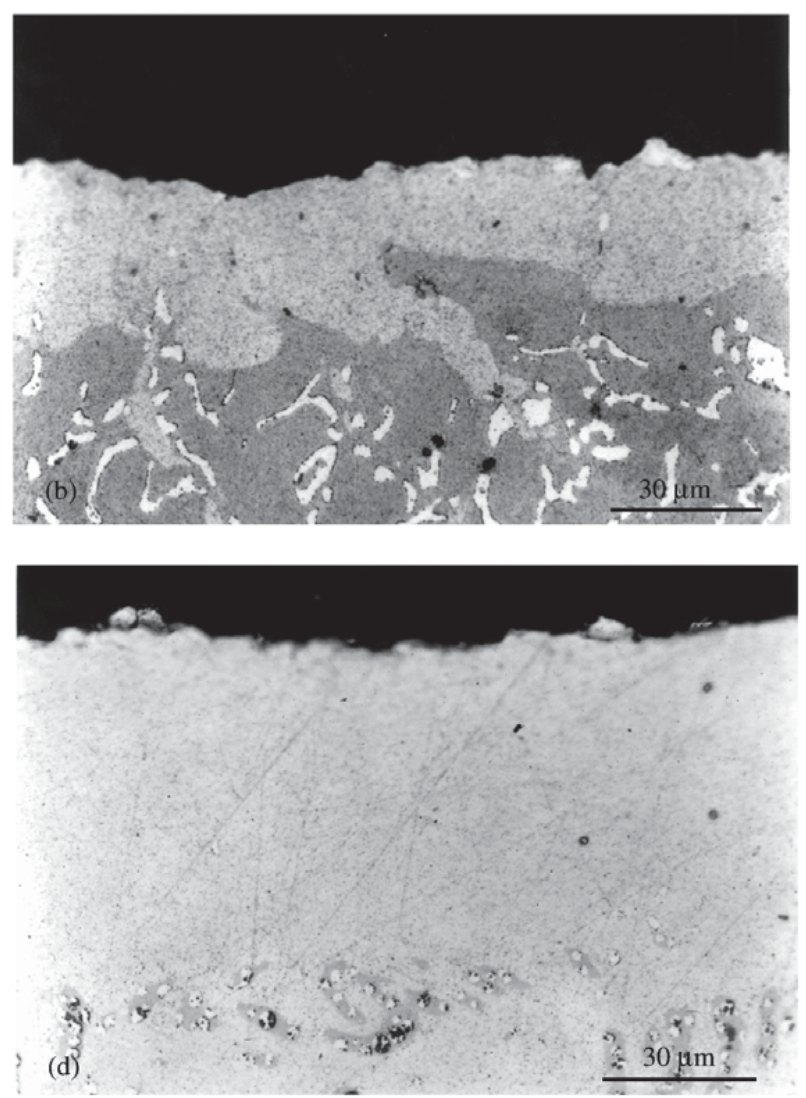

Figure 3. Cross-sections of alloys oxidised isothermally for 260 h: a) Alloy 2; b) Alloy 3; c) Alloy 5; d) Alloy 8. 


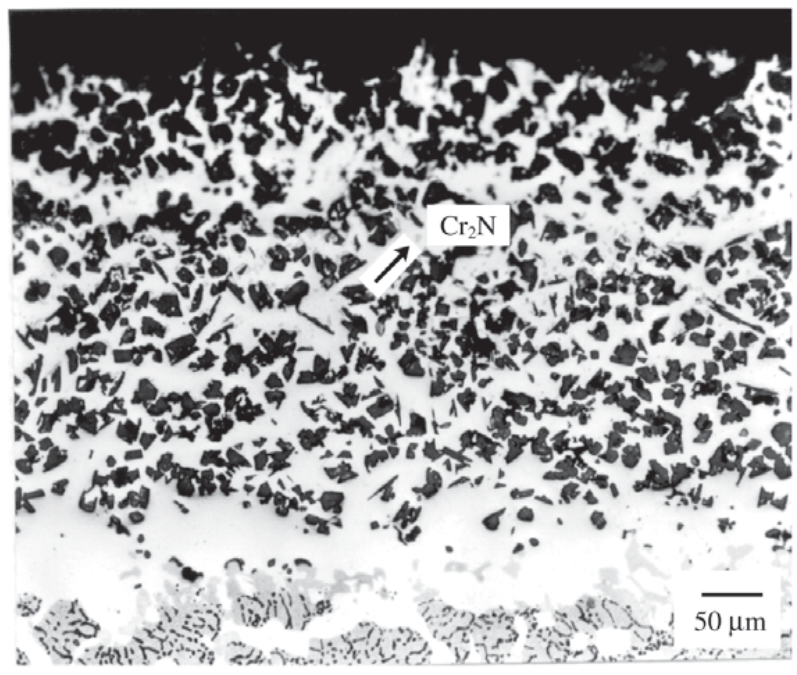

Figure 5. Cross-section of Alloy 1 after 260 cycles of reaction.

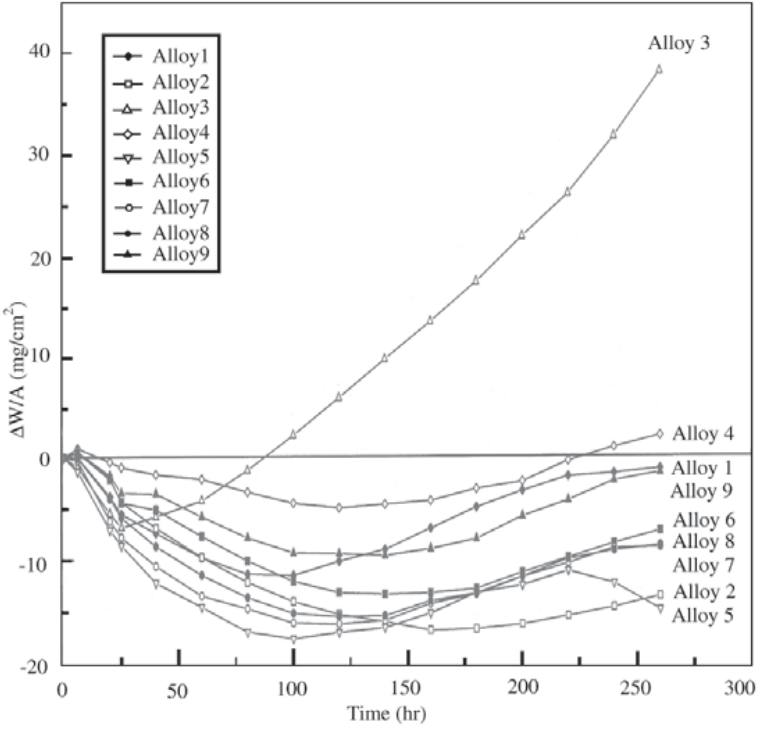

Figure 4. Weight change kinetics during cyclic oxidation ${ }^{5}$.

ess. As expected, the dissolution depths were greater in alloys of lower $\beta$-phase volume fraction. Whilst dissolution of the $\beta$-phase was rapid, that of $\alpha-\mathrm{Cr}$ was less so. The alloys with initial high $\alpha$ volume fractions (1, 2, 4, 6 and 9) still contained substantial amounts of the chromium-rich phase after $260 \mathrm{~h}$ of isothermal reaction. This reflected the differing driving forces for aluminium and chromium dissolution. The former was the large gradient in aluminium activity developed by the selective oxidation process. The latter, however, was the smaller, local gradient in chromium activity resulting from the increased solubility for chromium in $\gamma-\mathrm{Ni}$ developed as the aluminium concentration decreased.

The appearance of significant quantities of the $\alpha$-chromium phase at the reacted alloy surface is not predicted from the above model. As seen in Fig. 3b, the $\alpha$-phase had disappeared throughout most of the depletion zone but was still present at the alloy-scale interface, where chromium solubility in $\gamma-\mathrm{Ni}$ is expected to be highest and exposure to the dissolution process had occurred for the longest time. An alternative possibility is that the surface chromium had accumulated as a result of reduction by outwardly diffusing aluminium of early-stage transient $\mathrm{Cr}_{2} \mathrm{O}_{3}$.

\subsection{Cyclic Oxidation}

The overall weight change kinetics shown in Fig. 6 reflect the simultaneous loss of external scale through spallation and the development of internal precipitation product. In the early stage of reaction the spallation process was more important, leading to a net weight loss for all alloys. Evi-

In all alloys, the aluminium-rich $\beta$-NiAl phase had dissolved beneath the surface in response to the depletion proc- 


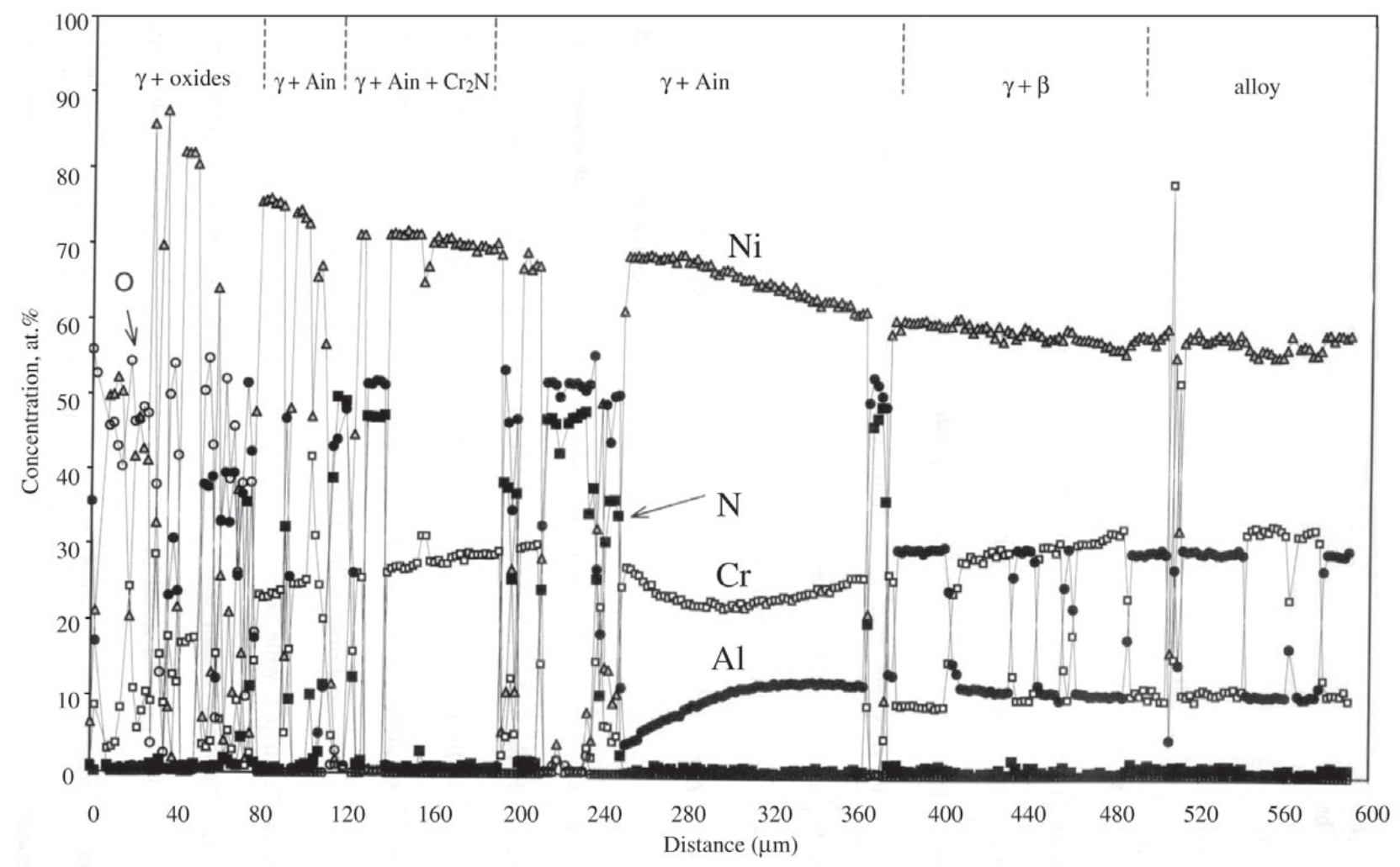

Figure 6. Microprobe analysis within subsurface zone of Alloy 5 after 260 cycles of reaction.

dently the scale damage occurring during isothermal oxidation became acute under the increased stresses resulting from thermal cycling. At longer times, as the rate of scaling decreased, the internal precipitation reactions produced weight increases. These balanced the weight loss caused by spallation, and eventually became the major process, leading to net weight increases for all alloys.

External scale constitutions reflected the selective oxidation of aluminium and chromium, and ultimately the development of nickel-containing oxide when scale rehealing capability was lost. The more stable $\mathrm{Al}_{2} \mathrm{O}_{3}$ was the early stage oxide scale as seen in the isothermal experiment. The repeated loss of this scale would have reduced the residual alloy aluminium concentration to the level where exclusive $\mathrm{Al}_{2} \mathrm{O}_{3}$ formation became impossible and chromium-rich oxides also formed. Further subsequent scale loss would then have reduced the chromium content also, eventually allowing the formation of $\mathrm{NiO}$ and spinel.

The very large extent of scale spallation is in agreement with earlier results on two-phase $(\alpha+\beta)$ alloys ${ }^{12,13}$ and single phase $\beta-\mathrm{NiAl}^{14}$. It is known that the presence of a separate alloy $\alpha$-chromium phase with its very different coeffi-

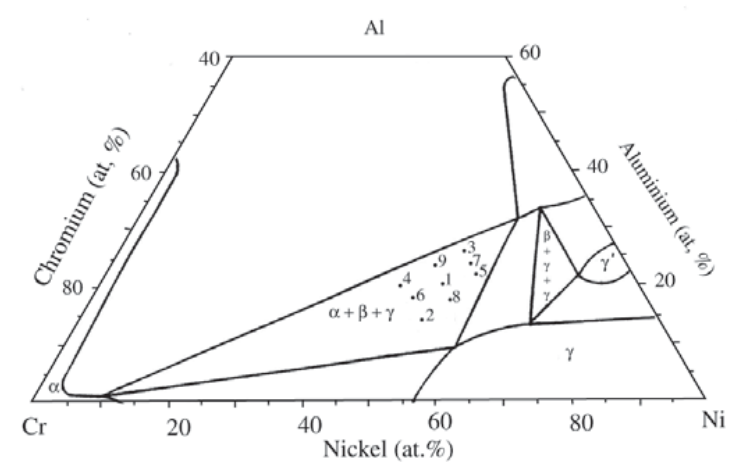

Figure 7. Isothermal section of $\mathrm{Ni}-\mathrm{Cr}-\mathrm{Al}^{12}$, showing schematic diffusion path for aluminium depletion.

cient of thermal expansion ${ }^{15}$ can promote spallation during temperature cycling.

Very extensive internal precipitation developed beneath the surface of every alloy. These reactions were accompanied by a transformation of the prior three phase alloy micro- 
structure into a single $\gamma$-phase in which the precipitates were embedded. The distribution of the internal precipitation products reflected their relative stability and the higher permeability of nitrogen ${ }^{16}$. Details of the precipitate distributions and the diffusion controlled growth of the precipitate zone are described elsewhere ${ }^{5}$. The general pattern was parabolic kinetics in the early stages of reaction followed by linear kinetics at long term. Alloy 3, however, displayed linear kinetics throughout the reaction.

The magnitude of the parabolic rate constant for internal precipitation has been shown ${ }^{5}$ to be consistent with control by inward diffusion of nitrogen. The long term linear kinetics which occurred at rates faster than could be sustained by metal matrix diffusion of nitrogen were attributed to gas phase transport occurring through parts of the reaction zone. This was a consequence of mechanical damage to the zone caused by stresses generated during thermal cycling, as a result of differences in thermal expansion coefficients between metal and precipitates.

Internal precipitation occurred within a matrix of single phase $\gamma$-nickel. As discussed earlier, selective oxidation of aluminium from these three-phase alloys must lead eventually to $\gamma$-phase formation. Because of the high permeability of nickel for both oxygen and nitrogen ${ }^{17-20}$ internal precipitation within this alloy sub layer was rapid, particularly in the case of nitridation.

\section{Conclusions}

Isothermal air oxidation of the $\gamma+\alpha+\beta$ alloys at $1100{ }^{\circ} \mathrm{C}$ produced scales of protective, self-healing $\alpha-\mathrm{Al}_{2} \mathrm{O}_{3}$. These scales grew according to parabolic kinetics, at rates typical of alumina formers.

Partial scale loss occurred during the course of isothermal reaction. However, in view of the magnitude of the overall rate constants and the fact that scales remained protective, it is concluded that scale damage was quickly repaired by scale regrowth.

Isothermally grown scales were protective and prevented nitrogen from reaching the underlying alloys.

Selective oxidation of aluminium and its depletion from the alloy subsurface region promoted phase transformations which were incomplete in the time scale of these experiments.

Cyclic air oxidation at $1100{ }^{\circ} \mathrm{C}$ produced much more damage. Repeated scale spallation led to initial weight losses, but subsequent extensive internal precipitation led to net mass gain. Sub-surface alloy depletion in aluminium and chromium caused transformation of the alloy microstructure to single phase $\gamma$-nickel.

The high permeability of $\gamma$-nickel for oxygen and nitrogen permitted rapid internal precipitate zone formation. The controlling process was initially diffusion of dissolved nitrogen through the nickel, but in the long term faster reac- tion rates reflected a contribution from gas phase mass transport in a mechanically disrupted alloy surface zone.

\section{Acknowledgements}

This work was supported by a grant from the Australian Research Council. S. Han gratefully acknowledges the receipt of an Australian Development Scheme Scholarship during the tenure of which this was carried out.

\section{References}

1. Snavely, C.A.; Faust, C.L. J. Electrochem. Soc., v. 97, n. 99, 1950.

2. Zheng, X.G.; Young, D.J. Mater. Sci. Forum, v. 251-254, 567, 1997.

3. Lai, G.Y. Proc. ASM 1993 Metals Congress - Materials Week 93, Advanced Materials and Coatings for Combustion Turbines, (Eds. V.P. Swaminathan and N.S. Cheruva, Pittsburgh, PA, 1993).

4. Chang, S.Y.; Krupp, U.; Christ, H.-J. in Cyclic Oxidation of High Temperature Materials, (Eds. M. Schutze and W.J. Quadakkers, p63 IOM Communications Ltd, London, 1999).

5. Han, S.; Young, D.J. Oxid. Met., v. 55, n. 225, 2001.

6. Giggins, C.S.; Pettit, F.S. J. Electrochem. Soc., v. 118, n. $1782,1971$.

7. Brum, M.W.; Grabke, H.J. Corros. Sci., v. 33, n. 1677, 1992.

8. Cheung, W.H. PhD Thesis, University of New South Wales, 1994.

9. Smialek, J.L.; Meier, G.H. Chapter 11 in Superalloys II Ed. C.T. Sims.

10. Doychak, J.; Smialek, J.L.; Barrett, C.A. in Oxidation of High Temperature Intermetallics, (Eds T. Grabstein and J. Doychak, TMS, Warrendale, PA, 1989).

11. Giggins, C.S.; Pettit, F.S. Trans. AIME, v. 245, n. 2495 1969.

12. Gleeson, B.; Cheung, W.; Young, D.J. Corrosion Sci., v. 35, n. 6923, 1993.

13. Prajitno, D.; Gleeson, B.; Young, D.J. Corrosion Sci., v. 39, n. 639, 1997.

14. Smeggil, J.G. Surf. Coat. Technol., v. 46, n. 143, 1991.

15. Lowell, C.E.; Garlick, R.G.; Henry, B. Met. Trans. A, v. 7A, n. 655, 1976.

16. Meijering, J.L. in Advances in Materials Research, $5^{\text {th }}$ ed, (Ed, H. Herman, Wiley-Interscience, New York, 1971).

17. Park, J.-W.; Altstetter, C.J. Met. Trans. A, v. 18A, n. 43, 1987.

18. Savva, G.C.; Weatherly, G.C.; Kirkaldy, J.S. Met. Trans. A, v. 27A, n. 1611, 1996.

19. Krupp, U.; Christ, H.-J. Oxid. Met., v. 52, n. 227, 1999.

20. Udyavar, M.; Young, D.J. Corrosion Sci., v. 42, n. 861, 2000. 